\title{
Corrosion-mechanical behavior of gas main steel in saline soils
}

\author{
Poberezhny L. ${ }^{1}$, Stanetsky A. ${ }^{1}$, Grytsuliak G. ${ }^{1}$, Poberezhna L. ${ }^{2}$, Kosmii M. ${ }^{3}$, Hrytsanchuk A. ${ }^{1}$ \\ ${ }^{1}$ Ivano-Frankivsk National Technical University of Oil and Gas, Ukraine \\ ${ }^{2}$ Ivano-Frankivsk National Medical University, Ukraine \\ ${ }^{3}$ King Danylo University, Ukraine \\ E-mail: lubomyrpoberezhny@gmail.com
}

The study of the deformation behavior of the pipeline material in conditions of loads and influences simulating the operation allows better estimation of the residual life of the pipelines and more accurate forecasting of the operating costs. The kinetics of deformation in 6 model environments simulating soil electrolytes was studied. Corrosion-mechanical tests were performed and the impact of the soil electrolyte chemical composition and the applied mechanical stresses on the corrosion behavior of the pipeline steel was studied. Significant increase in the corrosion activity of the soil electrolyte due to the synergistic effect of the corrosion-active components was found in the specified ratios of the ionic molar concentrations of sulphate and chloride ions (0.05 M: 0.1 M).

\section{INTRODUCTION}

Continuous exposure of stress field in soil massif on the metal of the pipeline causes different structural processes, the relaxation of internal stresses and deformation in general [1-3]. That is why, study of changes in physical and mechanical properties of the pipeline material in operation process will better determine the resource of gas pipelines constructions. Moreover, there is a rising importance of existing pipelines operability maintaining in today's conditions [4-7].

Inspection of underground pipelines showed that their life mainly depends on the corrosion resistance of the base metal and welded joints of pipes as well as the destruction of nature metal surface in places with broken insulation coating.

In construction the issues of gas pipelines interaction with soil is studied insufficiently. That is why there are no clear and proven solutions for selection or determination of the main characteristics for calculation and analysis of underground pipelines operation. The calculation of pipes laid down in the ground is done by applying the methods of underground structures mechanics. The pipe and the surrounding soil are treated as elements of a single deforming system that perceives external loads and impacts [8-10].

Taking into account the corrosion activity of the soil that is usually assessed by the time of the appearance of the first cavity on a new pipeline, composition and physical properties of soil and their dynamics complicates the calculation scheme. Also there are many additional and variable in time parameters that are taken not only from handbooks but also determined experimentally. List of only most significant factors determining the corrosion activity of soils, which are the structure and analysis, humidity, composition of the soil electrolyte, the total acidity or alkalinity of the soil, the concentration of hydrogen ions, air penetration redox potential, electrical resistivity of soils, indicate the complexity of the mathematical modeling of deformable system "pipe-soil massive" and thus prediction of the durability of the underground pipeline $[6,11]$.

\section{MATERIALS AND METHODS}

Gas mains of large diameter made of $19 \mathrm{G}$ steel, were chosen as the object of our research. It is known that the behavior of pipeline steel in soil in many ways is similar to its behavior when fully immersed in the solution with the appropriate $\mathrm{pH}[12,13]$. In this case electrochemical corrosion mechanism with formation of microgalvanic elements is predominant. However, in the underground pipeline, due to the heterogeneity of metal pipes and heterogeneity of the soil according to the physical properties and chemical composition, as well as various aeration, there appear areas in which the electrode potential is notably different, which leads to the formation of macrogalvanic corrosive elements. Some parts of pipes with more negative potential become anodic and areas with less negative potential become cathode. Six model environments (ME) of soil electrolytes were chosen for testing (Table 1). 
Tab. 1. Chemical composition of ME for tests

\begin{tabular}{|c|c|c|}
\hline \multirow{2}{*}{ № ME } & \multicolumn{2}{|c|}{ Concentration $\left[\mathbf{m o l ~ d m}^{-3}\right]$} \\
\cline { 2 - 3 } & $\mathbf{N a C l}$ & $\mathbf{N a}_{2} \mathbf{S O}_{\mathbf{4}}$ \\
\hline 1 & 0.01 & - \\
\hline 2 & 0.05 & - \\
\hline 3 & 0.1 & - \\
\hline 4 & 0.005 & 0.005 \\
\hline 5 & 0.025 & 0.025 \\
\hline 6 & 0.1 & 0.05 \\
\hline
\end{tabular}

It can be stated that the feature of underground pipeline corrosion is its expression in the form of pits and cavities (through holes) [14, 15]. Therefore, the main danger is not the corrosion loss of metal but local corrosion, which is a major cause of accidents on pipelines. To ensure safe operation of gas pipelines and forecasting the remaining work resource, it is extremely important to study the characteristics of corrosion degradation of the material of the linear section of underground pipelines in soils of different types. According to these characteristics some researches of synergistic action of corrosion and mechanical factors were done previously [16-20]. Samples were cut out from the pipes wall. The chemical composition of the $19 \mathrm{G}$ pipeline steel is shown in Table 2.

The study of deforming behavior of the steel under stress and impacts that imitate the operational ones will help to better assess the remaining life of existing gas pipelines safe operation and the service life of new gas pipelines. To predict more correctly operational risks and to assess the level of potential environmental threats caused by the operation of these technical objects it is particularly important to study the kinetics of deformation in corrosive environments. It is because the level of damage as a result of synergistic action of mechanical and corrosive factors increases nonlinearly, respectively increasing the possibility of seal failure or the destruction of the pipeline and thus the associated operational risks [21-23].

For the prediction of nonlinear processes it is necessary to accumulate a significant amount of experimentally obtained data about the impact of various factors (mechanical stress, chemical composition and ionic strength of the solution etc.) on the behavior of the pipeline material. This help to find the relationship between them and, after accumulating enough material, the selection of the main criteria (EP kinetics, kinetics of creep and corrosion creep, corrosion rate etc.) for the construction of the polycriterial model of the pipeline interaction with the environment.

The main goal of such research is the study of the impact of mechanical and corrosion factors on the kinetics of corrosion creep of the pipeline material. For this purpose a series of mechanical and corrosionmechanical tests were conducted in model environments that simulate the main types of soil and electrolytes and are divided into chloride and chloride-sulfate ones according to their chemical composition, and by their reaction into neutral and acidified. Mechanical testing was carried out on $\mathrm{KN}-1$ installation under pure bending load using stepwise method of loading and unloading of exposure at each stage for $20 \mathrm{~s}$ to study deeply the deformation behavior of steel pipe and to track processes of relaxation.

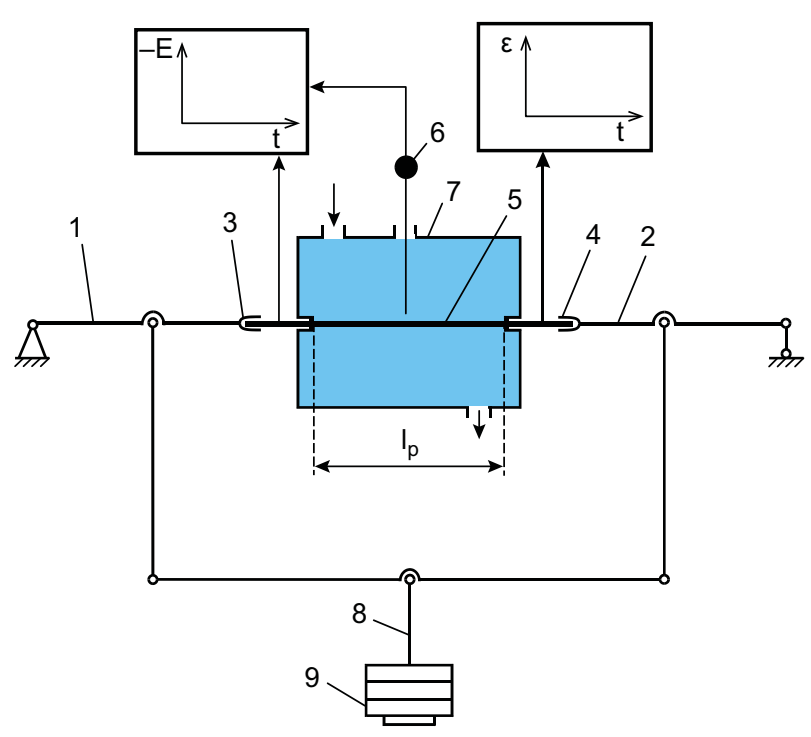

a)

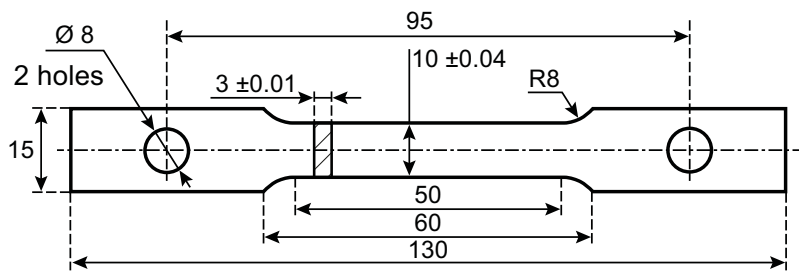

b)

Fig. 1. Scheme of $\mathrm{KN}-1$ installation (a) and test sample (b): 1, 2 - rotary plates; 3,4 - clamps; 5 - experimental sample; 6 - comparison electrode; 7 - removable working chamber; 8 - traction; 9 - variable loads

Tab. 2. Chemical composition of $19 \mathrm{G}$ steel (in \%)

\begin{tabular}{|c|c|c|c|c|c|c|c|c|c|c|}
\hline $\mathbf{C}$ & $\mathbf{S i}$ & $\mathbf{M n}$ & $\mathbf{N i}$ & $\mathbf{S}$ & $\mathbf{P}$ & $\mathbf{C r}$ & $\mathbf{N}$ & $\mathbf{C u}$ & $\mathbf{A s}$ & $\mathbf{F e}$ \\
\hline $0.16-0.22$ & $0.2-0.4$ & $0.7-1.0$ & $>0.3$ & $>0.04$ & $>0.035$ & $0.8-1.15$ & $>0.008$ & $>0.3$ & $>0.08$ & 97 \\
\hline
\end{tabular}


To study the kinetics of corrosion creep, using the bending chart built according to the results of mechanical tests of samples, cut from the pipe wall. Three levels of nominal stress according to the yield limit of pipeline steel $(1.05 ; 1.35$ and 1.65 of yield limit) were selected, which correspond to regular, non-regular (with higher level of exploitation loads) and extreme working modes of the pipe, and are 330, 420 and $510 \mathrm{MPa}$. To correctly identify the impact of corrosive environment on the deformation behavior of the steel pipe, creep was studied first in the air (simulating the operation of the pipeline with insulating coating intact) (Fig. 2) and in each of modeling environments (Fig. 3-4). Exposure time was 30000 minutes. During the experiment the kinetics of creep deformation $\left(\Delta \varepsilon_{\mathrm{c}}\right)$ and corrosion creep deformation was studied $\left(\Delta \varepsilon_{\mathrm{cc}}\right)[6]$.

\section{RESULTS AND DISCUSSIONS}

In the air we can see increasing kinetics (Fig.2) with extinction at the last stage and entering the plateau. With the increase of the nominal value of the stress the intensity of the process also increases.

At the top, near the border of strength stress in the creep curve we observed slopes. It is obviously, that such a deformation behavior may be caused by the proliferation of microcracks that determines the abrupt increase in strain. In the final section of slope creep curve, we can study the process of speed extinction. This parameter can be used as an additional criterion for evaluation and prediction of creep and corrosion creep - with its increasing the risk of bearing capacity loss as a result of negative synergistic action of mechanical stress and corrosive environment increases, and vice versa, with its reduction - decreases. In the transition to middle-level stresses we see almost monotonically increasing kinetics and while approaching the liquid limit - almost linear one. Comparing the nature of the process of evolution we can note that it reaches the final

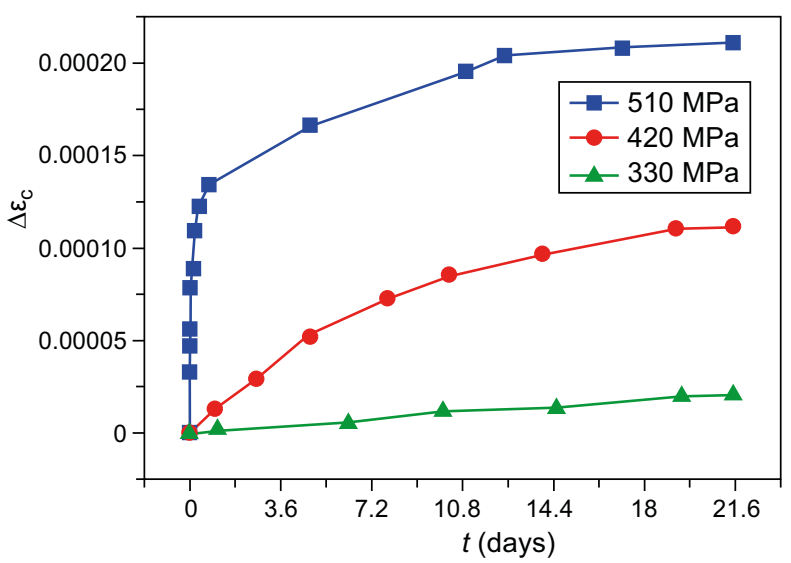

Fig. 2. Kinetics of pipeline steel creep in the air stage the fastest at $510 \mathrm{MPa}$, the longest at $330 \mathrm{MPa}$. Creep at $420 \mathrm{MPa}$ is characterized by the most even kinetics. At the same time, we observe the longest active creep evolution, $75 \%$ of the time we have very strong growth of creep deformation.

Kinetic's creep in chloride environments (Fig. 3) differs from the one in the air primarily by its monotony.

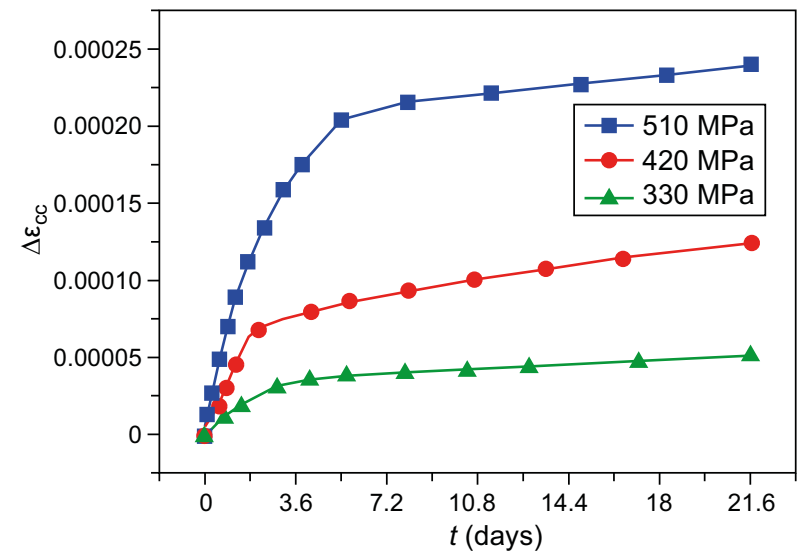

a) ME 1

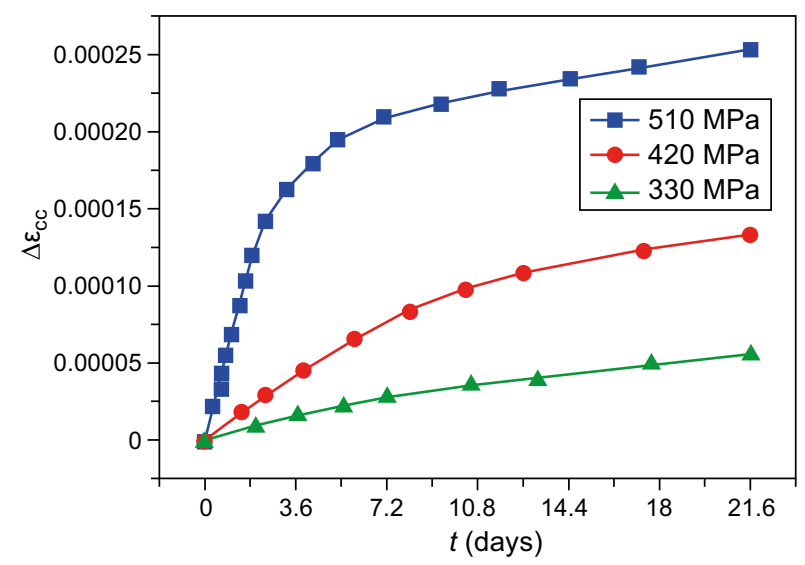

b) ME 2

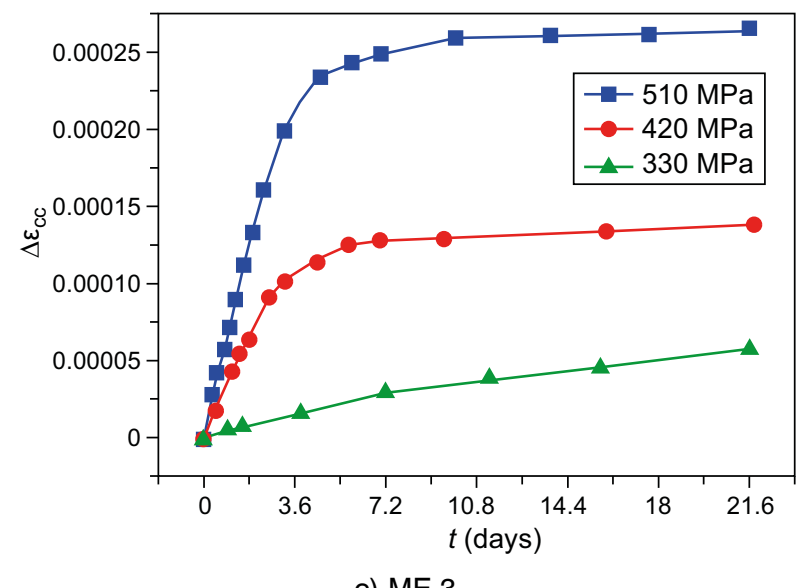

c) $\mathrm{ME} 3$

Fig. 3. Kinetics of pipeline steel creep in ME 1 (a), ME 2 (b) and ME 3 (c) 
Practically there are no sudden changes, only the absolute values of velocity and strain rate differ. The most likely it's a consequence of Rebinder's effect, which causes reduction of surface energy, facilitating the formation of a unit surface area and thus metal plastic flow. A significant decrease in the rate process of damping compared with the air should be also noted. It is particularly noticeable for the value of nominal stress $330 \mathrm{MPa}(1.05)$, where there is a growing kinetics of gradual process of damping, but without entering the plateau.

Such corrosion-mechanical behavior of pipe steel can be explained by synergistic effect of corrosion and mechanical factors as the level of stress, as shown by the results of the tests in the air is insufficient for such a long intense deformation rate. A major factor, that cause reduction of pipeline steel bearing capacity is the corrosion influence of soil electrolyte (due to the formation of new and development of existing defects) [4, 6-7, 21].This evidenced by the kinetics of deformation on the air with virtually the last horizontal section.

Corrosion processes facilitate the development of existing and cause accumulation of additional damage by dangerously reducing carrying capacity and creating additional risks in the normal modes of operation. These hidden risks must be detected on time to prevent damage to the pipeline and associated with them occurrence of contingencies. Phases of evolution of corrosion creep in chloride-sulfate environments (Fig.4) differs little from that in chloride electrolytes. The main difference is significantly greater increase in strain at equal values of nominal stress and accelerated passage of the first stage (intense deformation rate), especially in the ME4.

We can conclude that the chloride-sulfate electrolytes are much more dangerous from the point of view of corrosion. This is due to many factors, the most important of which is synergistic action of corrosive ions $\mathrm{Cl}^{-}$and $\mathrm{SO}_{4}{ }^{2-}$ found in previous studies [6] and cause the significant localization of corrosion processes. The same reason leads to accelerated growth of existing defects caused by the formation of galvanic couples "the old surface - the newly formed surface" or others with a similar mechanism. Dangerous overall kinetics of corrosion creep in ME5 and ME 6 should also be noted.

For all levels of stress we observe dangerously intense monotonic increase in strain, which indicates a constant appearance of new lesions and reduced bearing capacity. Such deformation behavior under operating conditions can cause depressurization of the pipeline and may lead even to emergency situation. There is a risk of leakage of transported product and damage of the environment along the route of the pipeline. Observed deformation behavior of steel pipe requires a thorough study to accumulate factual material for further development together with industry experts, modern new regulations and amendments to existing ones.
At the final stage the study of corrosion rate in model environments was done. This study concludes and summarizes a thorough evaluation of the processes of interaction of the steel pipeline with the environment considering the operational loads and impacts. The study of general and local corrosion rates was carried out. The rate of corrosion was estimated by the parameter K,

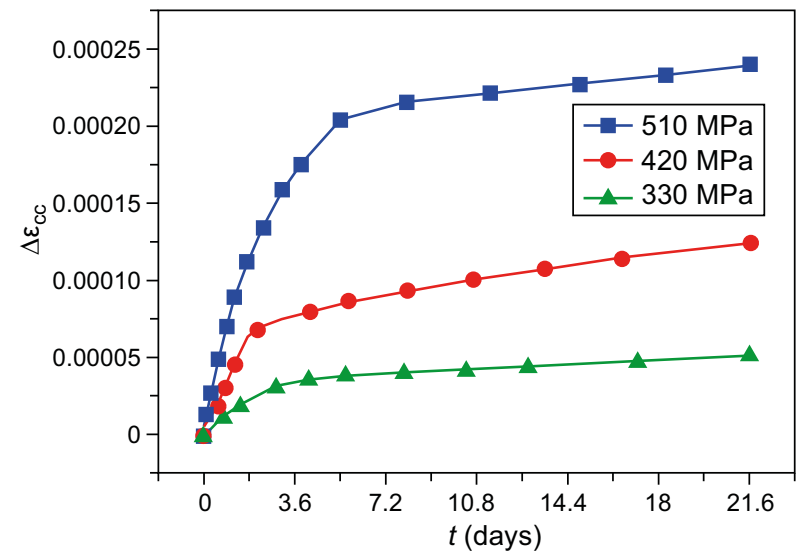

a) ME 4

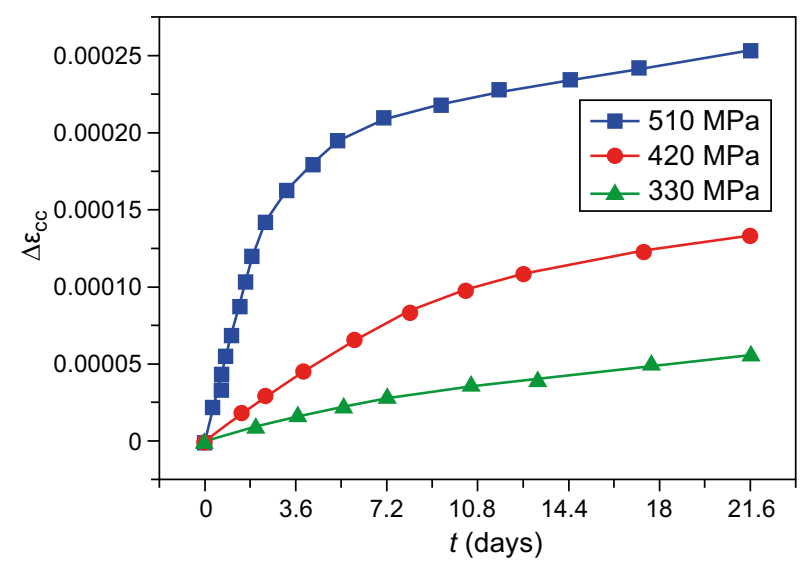

b) ME 5

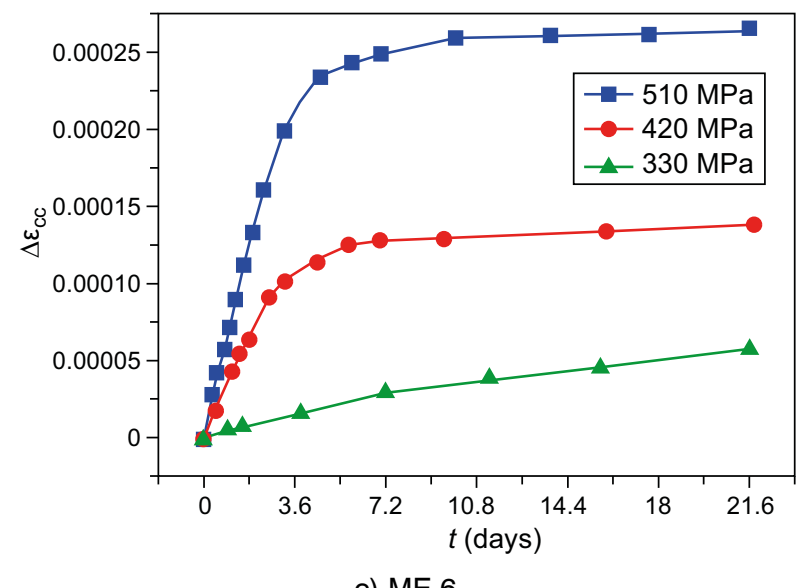

c) ME 6

Fig. 4. Kinetics of pipeline steel creep in ME 4 (a), ME 5 (b) and ME 6 (c) 
which was determined by the ratio between the weight of the metal before the corrosion test and after the test, and the investigated surface $\mathrm{S}$ and the time of the test. However, the weight index of the corrosion rate does not take into account the metal density. Therefore, it was recalculated to a depth index, which characterizes the thinning of the pipe wall [13].

The gravimetric method [24] is most commonly used for the assessment of corrosion resistance. It is used in two variants: determination of the increase in specimen mass as a result of formation of corrosion products on the specimen surface and determination of mass lose after the removal of corrosion products. The second variant is more commonly used due to its universality.

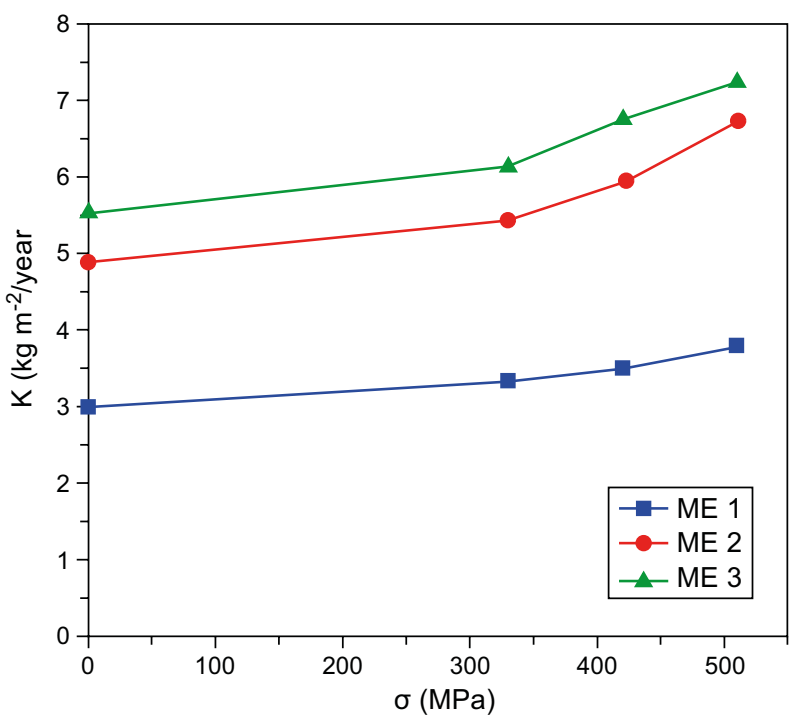

a) general corrosion

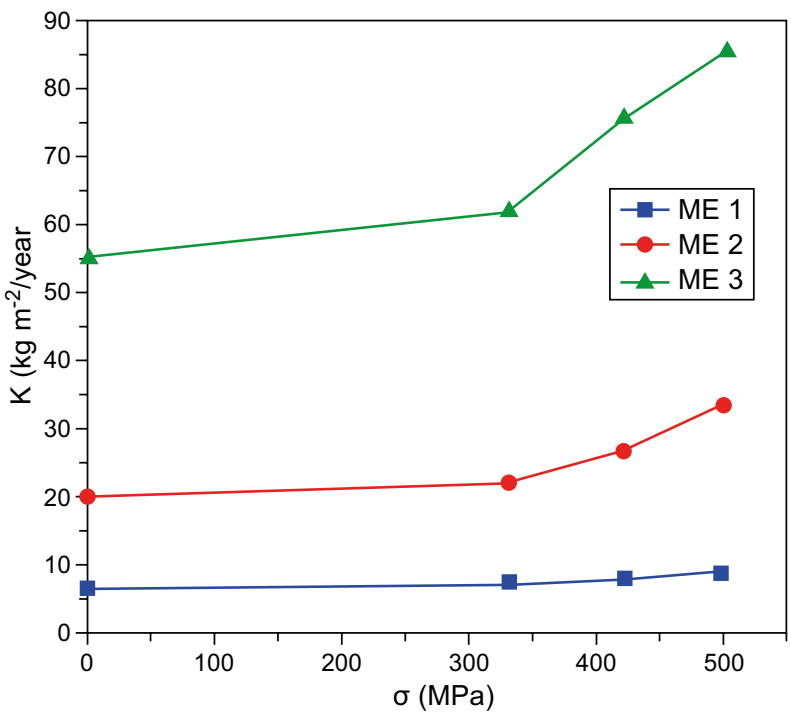

c) localized corrosion
The comparison of the amount of maximum corrosion damage, found from the depth of the largest cavities $(\mathrm{mm})$, with the amount of medium corrosion damage, calculated from mass lose $\left[\mathrm{kg}\left(\mathrm{m}^{-2}\right.\right.$ year $\left.\left.^{-1}\right)\right]$, makes it possible to estimate the degree of corrosion nonuniformity. This fact must be taken into account when determining the service life of pipelines since nonuniform corrosion leads to a sharp decrease in their stability through a change in mechanical properties with time [6].

Research in chloride environments showed (Fig. 5) a noticeable increase in the rate of general corrosion with increasing concentration of chloride ions in the transition from ME1 to ME2. and somewhat less in the transition from ME 2 to ME3.

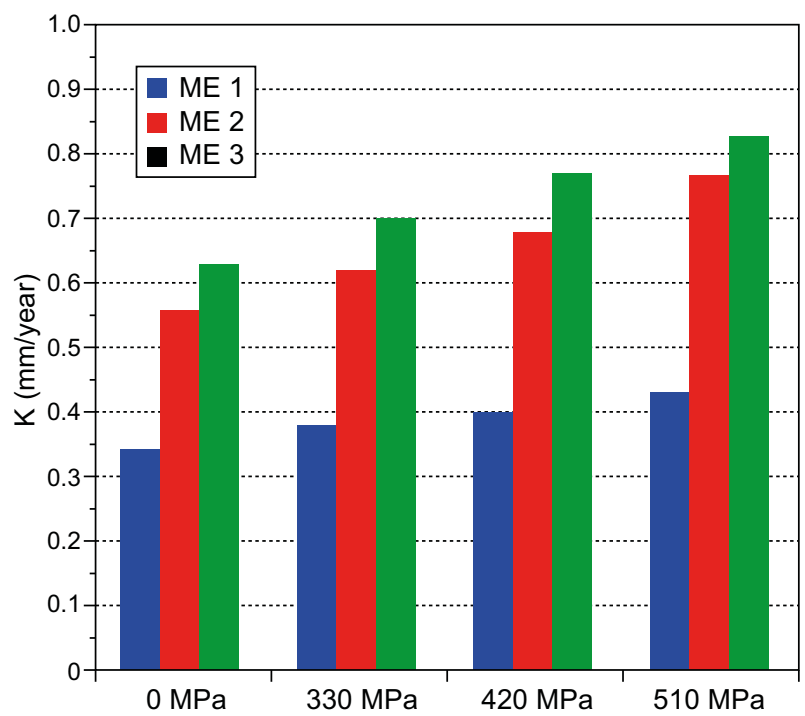

b) general corrosion

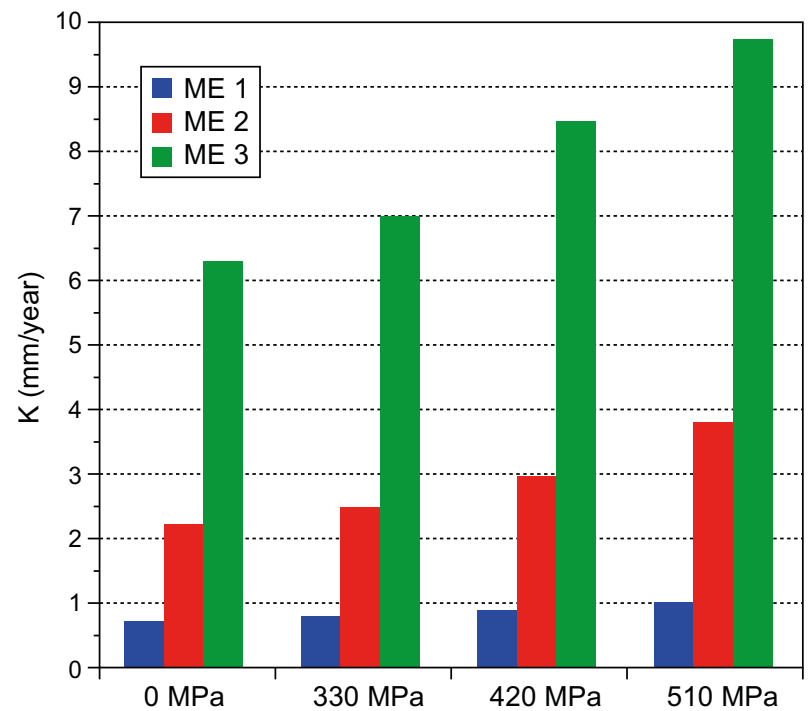

d) localized corrosion

Fig. 5. Influence of mechanical stresses on corrosion rate $(a, c)$ and pipeline wall thickness (b, d): general corrosion (a, b), localized corrosion (c, d) 
By comparing the speed of general and local corrosion we can reveal the bright intensification of local corrosion processes, and it increases with the increase of concentration of chloride ions. With the increase in the concentration of chloride ions, the action of the mechanical factor also increases significantly in case of general corrosion degradation and local corrosion.

In local corrosion with mechanical stress levels increasing we can see a significant intensification of corrosion processes, especially in the area of elasticplastic deformation (range $1.35^{\sigma_{0.2}^{*}}-1.65^{\sigma_{0.2}^{*}}$ ). The active growth of the rates of general and local corrosion was fixed, although in case ME1 the local corrosion rate increases slightly, due to the relatively small corrosion processes localization. For proper evaluation of operation

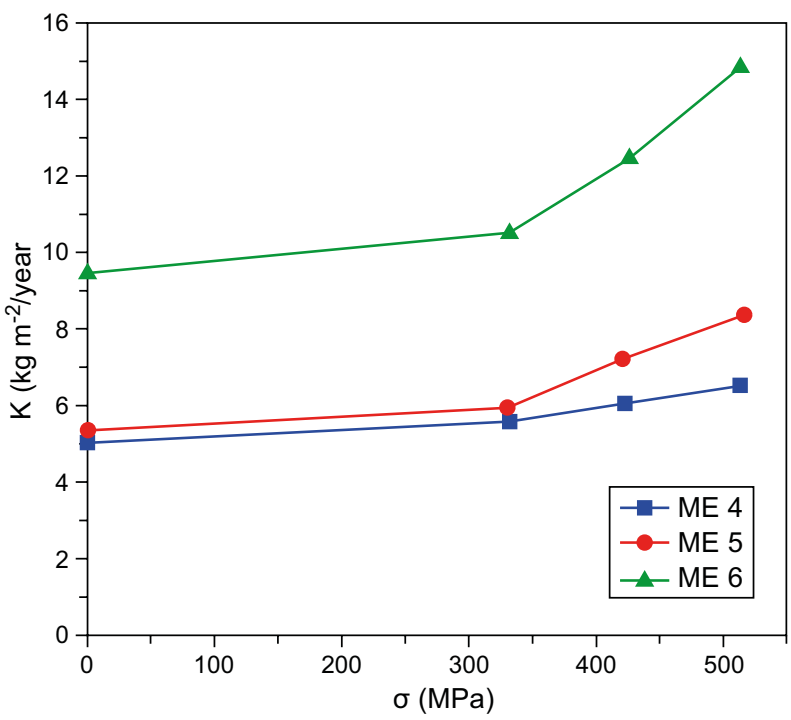

a) general corrosion

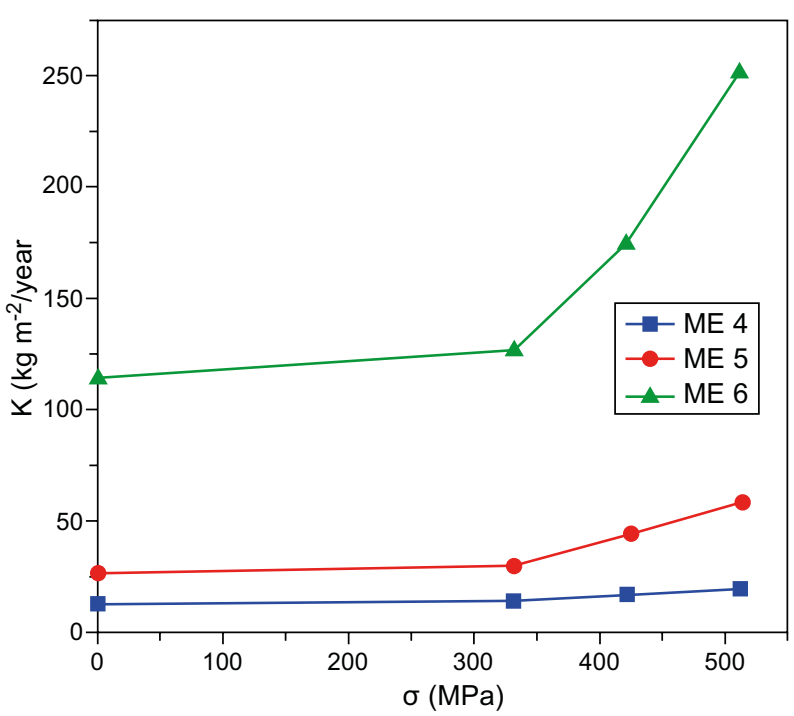

c) localized corrosion risks, resource and residual safety of operation, it is extremely important to know wall thickness corrosion rate (Fig. 5b,d) in the course of operation for the timely prevention of possible extraordinary situations.

It can be noted that in case of damage to insulation and the absence or improper quality of active corrosion protection, thinning in chloride environments in the area of operational loads can reach $0.45-0.55 \mathrm{~mm}$, and taking into account the localization process in case of ME3 it exceeds $6 \mathrm{~mm} /$ year, which testifies for the considerable danger of overpressure of pipelines, especially those that are used from 15 to 25 years with obsolete and degraded bituminous corrosion-resistant coatings [25-28]. It is particularly important to conduct groundwater analysis along pipelines' routes in order to timely assess

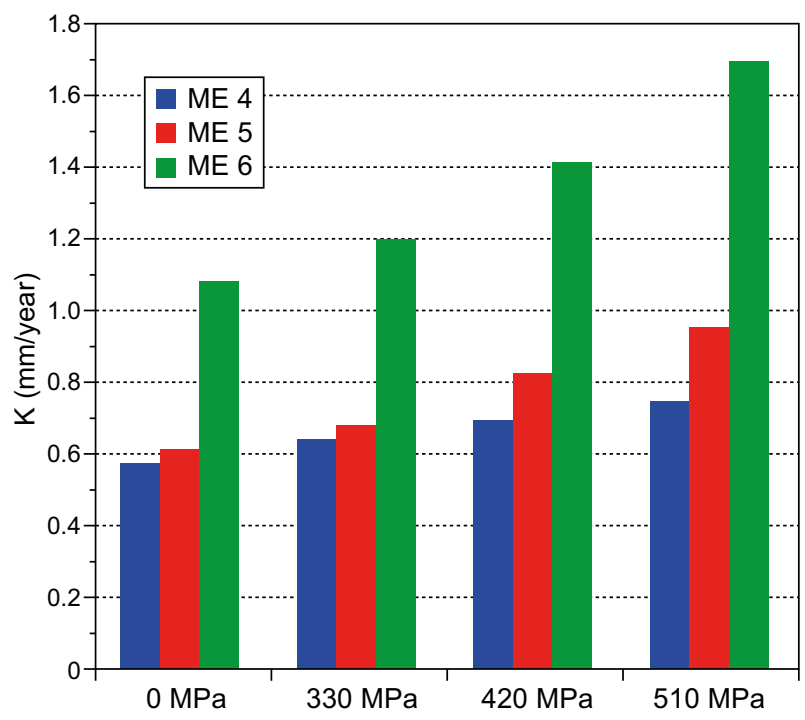

b) general corrosion

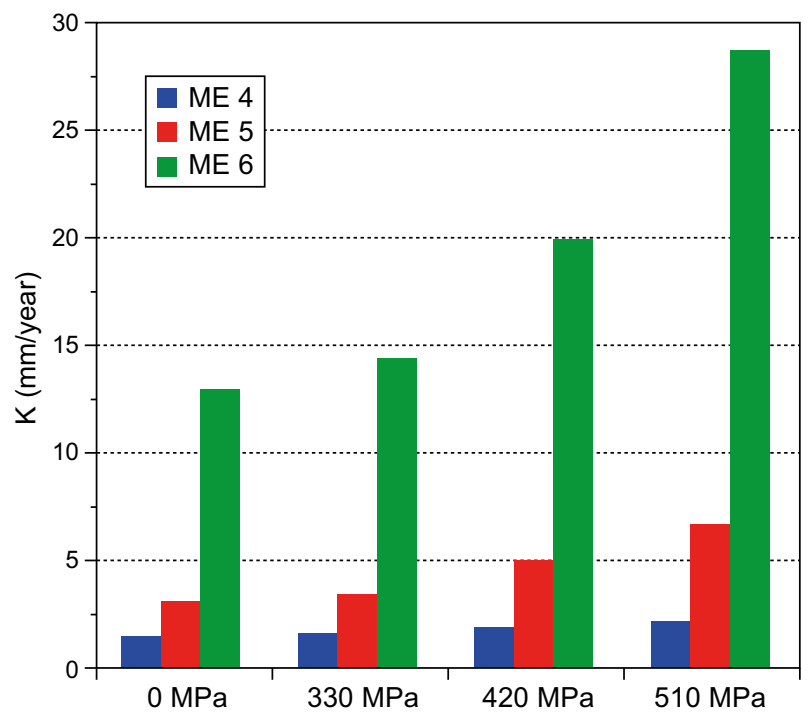

d) localized corrosion

Fig. 6. Influence of mechanical stresses on corrosion rate $(a, c)$ and pipeline wall thickness (b, d): general corrosion (a, b), localized corrosion (c, d) 
the risks of corrosion degradation of steel pipelines and prevent depressurization, or more severe failures and emergency situations [29, 30].

The next stage was the study of corrosive behavior in chloride-sulfate environment (ME4-ME6). This kind of soil electrolytes is characteristic for regions with high salinity of soils [31, 32].

Studies have shown (Fig. 6) an increase in the intensity of corrosion degradation with an increase in the level of mechanical stress in all three environments for both general and local corrosion. Such results correlate well with ones obtained during electrochemical tests values [33].

With an increase in the total concentration of chloride and sulfate ions, the speed of general and local corrosion increases, reaching a maximum in ME6. We can state that for the first time the ratio of ionic concentrations was found, in which the synergistic action of sulfate and ion chloride is so significant. Such an important conclusion can be made of Fig. 6 comparing the appearance of corrosion curves and the growth of corrosion rate in the transition from ME4 to ME5 and from ME5 to ME6 in the area of operating loads.

We observe a noticeable difference not only in the growth rate, but also in the increase of the intensity of corrosion degradation with an increase in the level of mechanical stress in the zone of elastic-plastic deformation. The last tendency was fixed also in the transition from ME4 to ME5 but its intensity is substantially smaller (except for the site 330-420 MPa). This difference is particularly significant in the development of local corrosion processes, where in the area of operating loads the corrosion rate in model environment ME6 is twice of that in ME5.

The detected dangerous patterns make it possible to assess as soon as possible the depression of the pipe wall under conditions of general and local corrosion in chloride-sulfate environment.

Studies show that in the area of operating loads, the rate of general corrosion for ME4 and ME5 is about $0.5 \mathrm{~mm} /$ year, for ME6 it is about $1 \mathrm{~mm} /$ year, which again confirms the danger of this ratio of molar ion concentrations.

This speed, even for ME4, indicates that it is necessary to revise existing estimates of the resource and the remaining safe operation resource in pipelines through zones of saline soils, and in case of revealing ratios of molar concentrations of ions close to those in ME 6, it is necessary to carry out a thorough, extensive examination of the quality of passive and active corrosion protection and determination of its level of damage, as well as the level of damage to the pipeline material by methods of non-destructive testing and internal purification dead diagnostic.

Particular attention should be paid to areas of probable additional mechanical loads. In the first place zones in landslide hazardous mountain areas, underground transitions through railways and highways. An assessment of the depletion of the pipeline wall due to the localization of corrosion processes in all chloridesulfate model environments showed that anomalous corrosion behavior was observed again in ME6. For the first time not only high corrosion rate was detected at a given ratio of ionic concentrations, but also extremely intensive localization of corrosion processes, as a result of which the rate of local corrosion in the area of operating loads may exceed $7-8 \mathrm{~mm} /$ year.

In the future researches it is necessary to study the impact of the pipeline's operation life and processes of structural degradation of the pipe material on corrosion behavior, because it is necessary for the estimation of long exploited pipelines residual life [34-36].

\section{CONCLUSIONS}

The corrosion creep of steel pipe in the air and in 6 model environments was determined and it was shown that the greatest risks of bearing capacity loss are in chloride-sulfate electrolytes.

Significant increase in the corrosion activity of the soil electrolyte due to the synergistic effect of the corrosion-active components was found in the specified ratios of the ionic molar concentrations of sulphate and chloride ions (0.05 M: 0.1 M).

The analysis of soil electrolytes along pipelines, especially those close to the planned exploitation resource, should be carried out as soon as possible. The obtained results indicate that in case of damage of the protective coating and improper anti-corrosion protection, their operation in areas with a detected dangerous relationship of ionic concentrations can lead to severe accidents with difficult predictive effects for the population and the environment.

\section{REFERENCES}

1. Meresht, E. S., Farahani, T. S., \& Neshati, J.: Failure analysis of stress corrosion cracking occurred in a gas transmission steel pipeline. Engineering Failure Analysis 2011, 18 (3), 963-970.

2. Azevedo, C. R. (2007). Failure analysis of a crude oil pipeline. Engineering Failure Analysis 2007, 14 (6), 978-994.

3. Paulin, M. J., Phillips, R., Clark, J. I., Trigg, A., Konuk, I.: A full-scale investigation into pipeline/soil interaction. In $19982^{\text {nd }}$ International Pipeline Conference (pp. 779-787). American Society of Mechanical Engineers, 1998.

4. Maruschak, P., Poberezhny, L., Pyrig, T.: Fatigue and brittle fracture of carbon steel of gas and oil pipelines. Transport 2013, 28 (3), 270-275.

5. Umbach, F.: Global energy security and the implications for the EU. Energy Policy 2010, 38 (3), 1229-1240. 
6. Poberezhnyi, L. Y., Marushchak, P. O., Sorochak, A. P., Draganovska, D., Hrytsanchuk, A. V., Mishchuk, B. V.: Corrosive and mechanical degradation of pipelines in acid soils. Strength of Materials 2017, 49 (4), 539-549.

7. Kryzhanivs'kyi, E. I., Hrabovs'kyi, R. S., Mandryk, O. M.: Estimation of the serviceability of oil and gas pipelines after long-term operation according to the parameters of their defectiveness. Materials Science 2013, 49 (1), 117-123.

8. Christoforidis, G. C., Labridis, D. P., Dokopoulos, P. S.: A hybrid method for calculating the inductive interference caused by faulted power lines to nearby buried pipelines. IEEE Transactions on Power Delivery 2005, 20 (2), 1465-1473.

9. Karamitros, D. K., Bouckovalas, G. D., Kouretzis, G. P.: Stress analysis of buried steel pipelines at strike-slip fault crossings. Soil Dynamics and Earthquake Engineering 2007, 27 (3), 200-211.

10. Pobereznyi,L.Y.,Poberezhna,L.Y.,Maruschak,P.O.,Panin, S. V.: Assessment of Potential Environmental Risks from Saline Soils Subsidence. In IOP Conference Series: Earth and Environmental Science (Vol. 50. No. 1. p. 012046). IOP Publishing, 2017.

11. Andreikiv, O. E., Ivanyts'kyi, Y. L., Terlets'ka, Z. O., Kit, M. B.: Evaluation of the durability of a pipe of oil pipeline with surface crack under biaxial block loading. Materials Science 2004, 40 (3), 408-415.

12. Alamilla, J. L., Espinosa-Medina, M. A., Sosa, E.: Modelling steel corrosion damage in soil environment. Corrosion Science 2009, 51 (11), 2628-2638.

13. Maruschak, P., Poberezny, L., Prentkovskis, O., Bishchak, R., Sorochak, A., Baran, D.: Physical and mechanical aspects of corrosion damage of distribution gas pipelines after long-term operation. Journal of Failure Analysis and Prevention 2018, 18 (3), 562-567.

14. Velázquez, J. C., Caleyo, F., Valor, A., \& Hallen, J. M.: Predictive model for pitting corrosion in buried oil and gas pipelines. Corrosion 2009, 65 (5), 332-342.

15. Saleem, B., Ahmed, F., Rafiq, M. A., Ajmal, M., Ali, L.: Stress corrosion failure of an X52 grade gas pipeline. Engineering Failure Analysis 2014, 46, 157-165.

16. Contreras, A., Hernández, S. L., Orozco-Cruz, R., GalvanMartínez, R.: Mechanical and environmental effects on stress corrosion cracking of low carbon pipeline steel in a soil solution. Materials and Design 2012, 35, 281-289.

17. Kryzhanivs'kyi, E. I., \& Nykyforchyn, H. M.: Specific features of hydrogen-induced corrosion degradation of steels of gas and oil pipelines and oil storage reservoirs. Materials Science 2011, 47 (2), 127-136.

18. Maruschak, P., Poberezny, L., Prentkovskis, O., Bishchak, R., Sorochak, A., Baran, D.: Physical and mechanical aspects of corrosion damage of distribution gas pipelines after long-term operation. Journal of Failure Analysis and Prevention 2018, 18 (3), 562-567.

19. Poberezhny’j, L. Ya.: Korozijno-mexanichna degradaciya magistralnyh gazoprovodiv. Naftovai Gazova Promyslovist 2011, 36-38. [in Ukrainian]

20. Alamilla, J. L., Oliveros, J., García-Vargas, J.: Probabilistic modelling of a corroded pressurized pipeline at inspection time. Structure and Infrastructure Engineering $\mathbf{2 0 0 9}$, 5 (2), 91-104.
21. Stanetsky, A. I.: Pipeline Steels Strain Behaviour in High Mineralized Soils. Scientific Bulletin of UNFU 2017, 27 (1), 175-177.

22. Yavorskyi, A. V., Karpash, M. O., Zhovtulia, L. Y., Poberezhny, L. Y., Maruschak, P. O.: Safe operation of engineering structures in the oil and gas industry. Journal of Natural Gas Science and Engineering 2017, 46, 289-295.

23. Brito, A. J., de Almeida, A. T.: Multi-attribute risk assessment for risk ranking of natural gas pipelines. Reliability Engineering and System Safety 2009, 94 (2), 187-198.

24. Oguzie, E. E., Unaegbu, C., Ogukwe, C. N., Okolue, B. N., Onuchukwu, A. I.: Inhibition of mild steel corrosion in sulphuric acid using indigo dye and synergistic halide additives. Materials Chemistry and Physics 2004, 84 (2-3), 363-368.

25. Lucca, G.: Electromagnetic interference from power lines on pipelines: influence of pipe insulating coating degradation. International Transactions on Electrical Energy Systems 2016, 26 (12), 2699-2712.

26. Manfredi, C., Otegui, J. L.: Failures by SCC in buried pipelines. Engineering Failure Analysis 2002, 9 (5), 495-509.

27. Roche, M., Melot, D., Paugam, G. (2006): Recent experience with pipeline coating failures. Journal of Protective Coatings and Linings 2006, 23 (10), 18.

28. Thompson, I., Saithala, J. R.: Review of pipeline coating systems from an operator's perspective. Corrosion Engineering, Science and Technology 2016, 51 (2), 118-135.

29. Gabetta, G., Nykyforchyn, H. M., Lunarska, E., Zonta, P. P., Tsyrulnyk, O. T., Nikiforov, K., M. I. Hredil, D. Yu. Petryna, T.: Vuherer (2008). In-service degradation of gas trunk pipeline X52 steel. Materials Science 2008, 44 (1), 104.

30. Maruschak, P., Panin, S., Danyliuk, I., Poberezhnyi, L., Pyrig, T., Bishchak, R., Vlasov, I.: Structural and mechanical defects of materials of offshore and onshore main gas pipelines after long-term operation. Open Engineering 2015, 5 (1).

31. Rogers, M. E., Grieve, C. M., Shannon, M. C.: The response of lucerne (Medicago sativa L.) to sodium sulphate and chloride salinity. Plant and Soil 1998, 202 (2), 271-280

32. Manchanda, H. R., Sharma, S. K., Bhandari, D. K.: Response of barley and wheat to phosphorus in the presence of chloride and sulphate salinity. Plant and Soil 1982, 66 (2), 233-241.

33. L. Ya. Poberezhnyi, Yu. P. Huzhov: Elektrokhimichni aspekty korozii mahistralnykh hazoprovodiv. Naftova $i$ Gazova Promyslovist 2005, 48-50. [in Ukrainian]

34. Poberezhnyi L. Ya.: Elektrokhimichna povedinka materialu naftohazoprovodiv u khlorydnykh ta khlorydno-sulfatnykh seredovyshchakh. Visnyk SNU 2007, 115 (9), 276-284. [in Ukrainian]

35. Maruschak, P., Bishchak, R., Prentkovskis, O., Poberezhnyi, L., Danyliuk, I., Garbinčius, G.: Peculiarities of the static and dynamic failure mechanism of long-term exploited gas pipeline steel. Advances in Mechanical Engineering 2016, 8 (4), 1687814016641565.

36. Ahammed, M.: Probabilistic estimation of remaining life of a pipeline in the presence of active corrosion defects. International Journal of Pressure Vessels and Piping 1998, 75 (4), 321-329. 